\title{
PRÁTICA SOCIAL EDUCATIVA EM ZILDA ARNS: pela memória, contra o esquecimento
}

\author{
SOCIAL AND EDUCATIONAL PRACTICE IN ZILDA ARNS: FOR MEMORY, \\ AGAINST FORGETFULNESS
}
PRÁCTICA SOCIAL EDUCATIVA EN ZILDA ARNS: POR LA MEMORIA, CONTRA EL OLVIDO

\author{
Claricia Otto* \\ D https:orcid.org/oooo-ooo1-8682-8332 \\ Fabiano Batista Rodrigues** \\ (iD https:orcid.org/oooo-0002-9579-6886
}

\begin{abstract}
REVISTA PEDAGÓGICA
Revista do Programa de Pós-graduação em Educação da Unochapecó | ISSN 1984-1566

Universidade Comunitária da Região de Chapecó | Chapecó-SC, Brasil

Como referenciar este artigo: OTTO, C.; RODRIGUES, F. B. Prática social educativa em Zilda Arns:

pela memória, contra o esquecimento. Revista Pedagógica, Chapecó, v. 22, p. 1-18, 2020. DOI: http://dx.doi.org/10.22196/rp.v22io.4682
\end{abstract}

\begin{abstract}
Resumo: Neste artigo, revisitamos memórias da médica pediatra Zilda Arns Neumann (1934-2010), fundadora e coordenadora da Pastoral da Criança até 2010, presentes em quatro documentos: duas entrevistas, uma concedida em 1998 e outra em 2003 e os textos Pastoral da Criança: uma experiência consagrada (2000), e Zilda Arns Neumann: ela criou uma rede de solidariedade que salva centenas de milhares de crianças brasileiras (2003). Na esteira das análises de Walter Benjamin - da vida moderna condenada a "não deixar rastros"; da exigência da memória e ao mesmo tempo sobre as dificuldades de narração da experiência comum, da transmissão e do lembrar - objetivamos rememorar aspectos da ação educativa de Zilda Arns não como comemoração e/ou formas de apologia, mas como uma reflexão sobre as incompletudes e esquecimentos no tempo presente. A reminiscência sobre a mobilização e adesão de milhares de voluntários à Pastoral da Criança leva a concluir que ela somente foi possível porque Zilda Arns construiu um método de justificativa dessa Pastoral estreitamente vinculado a uma mística que unia fé e ação por melhores condições de vida. Pelo caminho de uma metodologia de trabalho comunitário compreendido e assumido como missão, promoveu uma mobilização popular em torno de um objetivo comum: do compromisso com a justiça para a superação da exclusão social.
\end{abstract}

Palavras-chave: Memória. Zilda Arns. Pastoral da Criança. Prática social cristã.

Abstract: In this article, we revisit memories of pediatrician Zilda Arns Neumann (1934-2010), who founded and coordinated Pastoral da Criança until 2010. Memories are presents in four documents: two interviews, one in 1998 and another in 2003, and also in the texts Pastoral da Criança: uma experiência consagrada (Pastoral da Criança: a consecrated experience) (2010) and Zilda Arns Neumann: ela criou uma rede de solidariedade que salva centenas de milhares de crianças brasileiras (Zilda Arns Neumann: She created a solidarity network which saves thousands of Brazilian children) (2003). Based on Walter Benjamin analysis - from modern life condemned to "leave no trace"; from the memory exigence and, at the same time, about narration difficulties of common experience, transmission and remindness - we aim to remember aspects of Zilda Arns educational action not as a commemoration and/or an apology forms, but as a reflection about incompleteness and forgetfulness nowadays. Reminiscence about mobilization and accession of thousands of volunteers to Pastoral da Criança leads us to conclude that it was possible only because Zilda Arns build a justification method of this Pastoral which was strictly bound to a mystique that united faith and action for better living conditions. Along the way of a community work methodology understood and assumed as a mission, she promoted a popular mobilization around a common objective: commitment to justice for overcoming social exclusion.

Keywords: Memory. Zilda Arns. Pastoral da Criança. Christian social practice.

Resumen: En este artículo, revisamos memorias de la médica pediatra Zilda Arns Neumann (1934-2010), 
fundadora y coordinadora de la Pastoral del Niño hasta 2010, presentes en cuatro documentos: dos entrevistas, una concedida en 1998 y otra en 2003 y los textos Pastoral da Criança: uma experiência consagrada (2000), y Zilda Arns Neumann: ela criou uma rede de solidariedade que salva centenas de milhares de crianças brasileiras (2003). Con base en los análisis de Walter Benjamin - de la vida moderna condenada a "no dejar huellas"; de la exigencia de la memoria y al mismo tiempo sobre las dificultades de narración de la experiencia común, de la transmisión y del recordar objetivamos rememorar aspectos de la acción educativa de Zilda Arns, no como conmemoración y/o forma de apología, sino como una reflexión sobre las incompletudes y el olvido en el tiempo presente. La reminiscencia sobre la movilización y adhesión de miles de voluntarios a la Pastoral del Niño lleva a concluir que ella sólo fue posible porque Zilda Arns construyó un método de justificación de esa Pastoral estrechamente vinculado a una mística que unía fe y acción por mejores condiciones de vida. Por el camino de una metodología de trabajo comunitario comprendido y asumido como misión, promovió una movilización popular en torno a un objetivo común: del compromiso con la justicia para la superación de la exclusión social.

Palabras clave: Memoria. Zilda Arns. Pastoral del Niño. Práctica social cristiana.

\section{Introdução}

A biografia histórica, hoje reabilitada, não tem por vocação esgotar o absoluto do 'eu' de um personagem, como já se quis e ainda se quer [...]. Ela é o melhor meio de mostrar os laços entre passado e presente, memória e projeto, indivíduo e sociedade e de experimentar o tempo como prova de vida (LÉVILLAIN, 2003, p. 176).

Zilda Arns nasceu em 1934 numa colônia agrícola fundada por imigrantes europeus, denominada Forquilhinha, no interior de Santa Catarina. Era a décima segunda filha de 13 irmãos, dentre os quais seis tornaram-se religiosos, incluindo uma irmã adotiva. Na primeira entrevista, em 1998, Zilda afirma: a "religião ocupava um lado cultural muito grande - até hoje - e creio que é por isso que toda a família, não só os consagrados, é muito religiosa”.

Foi casada por dezoito anos com Aloísio Bruno Neumann, ficando viúva com cinco filhos, o mais novo de quatro anos e o mais velho de quatorze. Lembra que naqueles tempos de sua infância e juventude, "mal sabia que existia governo", que a escola, a biblioteca pública, a igreja e as casas do padre e das freiras foram construídas pela comunidade e que havia "uma atividade comunitária muito intensa". Zilda enfatiza: "tínhamos uma vivência familiar fortíssima. Todas as noites nos reuníamos para rezar e cantar a três, quatro vozes" (ENTREVISTA, 1998).

Nessa mesma entrevista, quando indagada a respeito de ter pensado em seguir a Vida Religiosa já que tinha seis irmãos que haviam seguido, recordou de, aos quinze anos de idade, ter assistido filmes. Um desses filmes, que tratava sobre missionários da Congregação Mariana do Bom Jesus, impressionou-lhe. Eram missionários do Amazonas, cuidando das comunidades ribeirinhas, localidade de muitas pessoas pobres. Teria dito: "vou ser médica e vou para o Amazonas andar de barco". Na citada entrevista,
* Doutora em História pela UFSC. Professora do Programa de Pós-Graduação em Educação da UFSC. Vice-líder do Grupo de Pesquisa Patrimônio, Memória e Educação (PAMEDUC). E-mail: clariciaotto@gmail.com.

** Mestre em Educação pela UFSC. Integra o Grupo de Pesquisa Patrimônio, Memória e Educação (PAMEDUC). E-mail: fabianorodriguesctba@gmail.com. 
rememora, ainda, outro filme que versava sobre as favelas do Rio de Janeiro, diante do qual também teria falado: "olha, confirmou minha vocação, eu vou ser médica".

Cursou medicina na Universidade Federal do Paraná (UFPR), entre 1954 e 1959, e se especializou em pediatria e sanitarismo. Durante o curso e nos dez anos seguintes trabalhou no Hospital Materno Infantil de Curitiba. Entre os anos 1960 e 1980 também atuou como coordenadora de entidades filantrópicas, na expansão de postos de saúde, clubes de mães, programas de incentivo ao aleitamento materno, higiene, vacinação, entre outros.

Desde a fundação da Pastoral da Criança, em 1983, e como primeira coordenadora dessa Pastoral, tanto no que escreveu, quanto na sua ação, sempre aderiu a valores religiosos com intensidade, cultivados desde a infância. ${ }^{1}$ Seu trabalho de dar prosseguimento à implantação de medidas para salvar vidas e/ou cicatrizar as chagas sociais, dentre as quais a desnutrição infantil, estava por ela sendo feito em Porto Príncipe (Haiti) quando foi atingida pelo terremoto levando à sua trágica morte, em 2010.

Cientes da impossibilidade e sem a pretensão de aqui arrolar toda a trajetória de Zilda Arns Neumann, ressalvamos que o percurso da vida de uma pessoa não se resume na linearidade com que são tecidas as narrativas memorialísticas. Também Bourdieu (2006, p. 190) faz esse alerta na "ilusão biográfica", salientando que a trajetória de um indivíduo somente pode ser compreendida no "conjunto das relações objetivas que uniram o agente considerado [...] ao conjunto dos outros agentes envolvidos no mesmo campo e confrontados com o mesmo espaço dos possíveis”.

Conforme já indicamos no resumo deste artigo, tomamos como principais fontes de reflexão narrativas testemunhais da própria Zilda Arns Neumann. Trata-se de duas entrevistas, uma de 1998 e outra de 2003. ${ }^{2}$ Alberti (2004, p. 147, grifos da autora) diz que "a entrevista não é 'apenas uma versão' e sim documento de uma realidade que diz respeito à formação e ao modo de atuação de certos segmentos da sociedade brasileira que detêm responsabilidades no plano político e intelectual". Nessa compreensão, a entrevista guarda a potencialidade de documento e, como tal, é passível de análise.

Além das referidas entrevistas, analisamos as obras, Pastoral da Criança: uma experiência consagrada (2000), produzida com vistas a justificar a Pastoral da Criança e contar sobre os primeiros anos dessa Pastoral no país, e Zilda Arns Neumann: ela criou uma rede de solidariedade que salva centenas de milhares de crianças brasileiras (2003), que reúne lembranças variadas seguindo uma perspectiva autobiográfica, de natureza testemunhal.

Nessas fontes é possível identificar um trabalho memorialístico em que Zilda Arns conta a história da Pastoral, ou seja, todos os quatro documentos se constituem como um trabalho de memória, de testemunho pessoal. Nesse sentido, Zilda Arns fala e escreve como testemunha direta,
1 Sem espaço para aqui tratar sobre o estado da arte de pesquisas sobre a Pastoral da Criança, sugerimos a leitura de Bertol e Paula (2018). 
que esteve presente, que viu a desigualdade social, a desnutrição, a desidratação e a morte de crianças como um escândalo social e que agiu, planejou, orientou mães, formou e multiplicou lideranças, entre outras práticas.

Todavia, propomos aqui uma reflexão do conceito de testemunha conforme cunhado por Benjamin que, segundo Gagnebin (2004, p. 91), estudiosa do pensamento benjaminiano, precisa ser compreendido sob um prisma mais amplo:

\begin{abstract}
A testemunha não seria somente aquele que viu com os próprios olhos, o histor de Heródoto, a testemunha direta. Testemunha também seria aquele que não vai embora, que consegue ouvir a narração insuportável do outro e que aceita que suas palavras revezem a história do outro: não por culpabilidade ou por compaixão, mas porque somente a transmissão simbólica, assumida apesar e por causa do sofrimento indizível, somente essa retomada reflexiva do passado pode nos ajudar a não repeti-lo infinitamente, mas a ousar esboçar uma outra história, a inventar o presente.
\end{abstract}

Gagnebin (2004) explica que a figura dessa narração de Benjamin remete ao sonho do Primo Levi, no campo de Auschwitz. Primo Levi sonha que na volta para casa busca contar sobre os horrores vividos na guerra e entra em desespero porque ninguém o escuta, todos os ouvintes ficam indiferentes, levantam-se e vão embora.

Salvaguardados os distintos contextos, aventamos uma analogia com a narração de Zilda Arns. Se Primo Levi representa uma narrativa "insuportável, indizível", ou seja, que não consegue falar da experiência do horror da guerra e também não encontra ouvintes dispostos a ter sua tranquilidade ameaçada, Zilda Arns, no fim do século XX e início do século XXI tece uma narrativa que remete a outro horror: o da fome, da desnutrição e da morte de milhares de crianças brasileiras e de outros países. Nessa perspectiva, os responsáveis por políticas sociais e todos nós estamos diante de uma escolha, a de sermos testemunhas no sentido benjaminiano ou nos portarmos tal como os (não) ouvintes do Primo Levi. A exigência de memória pode ser um caminho para não ficarmos alheios ao sofrimento e às necessidades do outro, pois "a rememoração também significa uma atenção precisa ao presente, particularmente a estas estranhas ressurgências do passado no presente, pois não se trata somente de não esquecer o passado, mas também de agir sobre o presente. A fidelidade ao passado, não sendo um fim em si, visa à transformação do presente" (GAGNEBIN, 2004, p. 89).

Nesse alinhamento benjaminiano, da narração que ocupa o lugar central e do personagem narrador que realiza um trabalho de memória, objetivamos trazer à baila 
aspectos da ação da líder da Pastoral da Criança não no intuito de que sirvam de exemplo para ações no presente e no futuro, mas sim de que o processo de rememoração aponte para aquilo que não foi realizado, para as esperanças e desejos não cumpridos. Em outras palavras, para os esquecimentos e incompletudes de uma sociedade que ainda gera exclusão de pessoas, principalmente de crianças que morrem de fome.

Nessa direção, na primeira seção abordamos alguns aspectos do contexto político e eclesial experimentados por Zilda Arns, provavelmente por ela apropriados e (re)significados quando fundou a Pastoral da Criança em 1983 e ao longo dos 27 anos em que foi coordenadora desta Pastoral. Por ser uma organização do terceiro setor, termo utilizado para definir instituições privadas e organizações sem fins lucrativos que promovem a solidariedade social, também realizamos uma digressão desse organismo social naquele contexto. ${ }^{3}$ Entender aspectos vividos pela Igreja Católica do período e da concepção cristã de caridade assumida por grupos de voluntários católicos que os leva a praticar uma assistência social baseada no amor fraterno aos carentes, crianças abandonadas, entre outras, sem esperar recompensas materiais para si próprios, contribui para entender os contornos de ação da organização da Pastoral da Criança.

$\mathrm{Na}$ segunda seção identificamos a apropriação de discursos eclesiais no então cenário social e político como decisivos na atuação do organismo social que criou uma rede de solidariedade, arrebanhando mais de 150 mil voluntários por todas as dioceses do país.

\section{Gênese da Pastoral da Criança: uma organização do terceiro setor entre luzes e sombras}

O narrador e o historiador deveriam transmitir o que a tradição, oficial ou dominante, justamente não recorda. Essa tarefa paradoxal consiste, então, na transmissão do inenarrável, numa fidelidade ao passado e aos mortos, mesmo - principalmente - quando não conhecemos nem seu nome nem seu sentido (GAGNEBIN, 2004, p. 88-89).

A epígrafe desta seção, impregnada da filosofia benjaminiana, propicia que narremos tendo presentes os muitos tempos de que é tecido o tempo histórico. As teses sobre o conceito de história que Benjamin (1987), especialmente as teses 6,16 e 17, tecem críticas a uma historiografia que lança o olhar ao passado tão somente com vistas a construir uma história universal ou eternizada. Já que para Benjamin a realidade (modernidade) é um palco de catástrofes e de escombros, o historiador e o narrador não podem fugir à tarefa de "transmissão do inenarrável”, ou seja, do horror nos diferentes tempos. Na tese 8, Benjamin (1987, p. 226)
3 Além do que apresentamos mais adiante neste artigo, para uma historicização do conceito e do debate sobre o terceiro setor indicamos Calegare e Júnior (2009). 
chama atenção para o fato de que é preciso construir um conceito de história que corresponda à verdade da "tradição dos oprimidos (a qual) nos ensina que o 'estado de exceção' em que vivemos é na verdade a regra geral”. Da tese 7 recortamos o seguinte fragmento:

Todos que até hoje venceram participam do cortejo triunfal, em que os dominadores de hoje espezinham os corpos dos que estão prostrados no chão. Os despojos são carregados no cortejo, como de praxe. Esses despojos são os chamados bens culturais. [...] Nunca houve um monumento da cultura que não fosse também um documento da barbárie. E, assim como a cultura não é isenta de barbárie, não o é, tampouco, o processo de transmissão da cultura. Por isso, na medida do possível, o materialista histórico se desvia dela. Considera sua tarefa escovar a história a contrapelo (BENJAMIN, 1987, p. 225).

Löwy (2005, p. 74), nas leituras das teses "sobre o conceito de história", diz que para Benjamin "escovar a história a contrapelo" tem duplo significado: "ir contra a corrente da versão oficial da história, opondo-lhe a tradição dos oprimidos. [...] a redenção/revolução não acontecerá graças ao curso natural das coisas, [...] o progresso inevitável”.

Zilda Arns, ao rememorar como se tornou coordenadora da Pastoral da Criança, diz ter recebido um telefonema de seu irmão Dom Paulo Evaristo Arns, arcebispo de São Paulo, que voltara de Genebra, de uma reunião da Organização das Nações Unidas (ONU) sobre a paz. Nesse telefonema, Dom Paulo teria dito: "Zilda, James Grant, o diretor-executivo da Unicef, disse que a Igreja poderia salvar muitas crianças da desnutrição, da ignorância das mães, se realmente fizesse um bom trabalho junto às famílias. Você não quer fazer um plano?"4 Ao rememorar esse convite, diz: "Senti que esta seria minha nova missão como profissional e cristã [...] sentia em mim essa vocação de aproveitar todas as oportunidades para reforçar a educação" (NEUMANN, 2000, p. 84).

Em suas memórias, recorda que, sentada na sala da Unicef, em Brasília, começou a escrever o plano e teve a ideia de seguir a metodologia do milagre da multiplicação dos cinco pães e dois peixes, que saciou a fome de 5 mil pessoas, tal como narrado pelo evangelho de São João. Como conhecia a Igreja Católica e a Saúde Pública, pensou em trabalhar com a Igreja e com as famílias. O Plano foi acolhido pelo então diretor da Unicef no Brasil, Jacob Mattai, e assim foi apresentado ao bispo Ivo Lorscheider, então presidente da Conferência Nacional dos Bispos do Brasil (CNBB) e a Dom Luciano Mendes de Almeida, secretário geral. Dom Paulo sugeriu começar em Londrina (PR), com Dom Geraldo Magela Agnelo, pois esse bispo já havia coor-
4 O Unicef é o Fundo das Nações Unidas para a Infância, com sede em Nova York (EUA). Teve sua fundação em 1946 com objetivo de ajudar na reconstrução dos países mais afetados pela Segunda Guerra Mundial e passou a atuar em outras nações quatro anos depois. Hoje, está presente em 191 países. Desde 1950, o Unicef está no Brasil e trabalha em parceria com o governo nas esferas municipal, estadual e federal, sociedade civil, grupos religiosos, mídia, setor privado e outras organizações internacionais, incluindo agências das Nações Unidas. Ver em: <https://www.unicef.org/brazil/pt/>. 
denado pastorais sociais em São Paulo. A opção foi começar na diocese de Londrina, no município de Florestópolis, onde a mortalidade infantil era alta, com 127 mortes por mil crianças nascidas vivas. A paróquia foi dividida em pequenas quadras, foram escolhidas e formadas lideranças para cada quadra e após oito meses a mortalidade infantil já havia sido reduzida. As ações básicas consistiam na utilização do soro caseiro, amamentação, vigilância nutricional, vacinação e cuidado com as gestantes. Dessa experiência inicial o trabalho se expandiu para diversas regiões do Brasil. Zilda Arns relembra:

Fui primeiro para Maceió, uma favela chamada Brejal, com 4 mil favelados morando em casinhas que afundavam por causa do brejo, uma dificuldade tremenda, uma mortalidade de três, quatro mortes por dia. E, então, nós começamos lá e depois fomos até Bacabal, no Maranhão, no Rio Grande do Sul, em Santo Antônio da Patrulha, fomos para São Paulo [...]. Eu mesma treinava as líderes e escrevia materiais sobre aleitamento materno, hidratação oral e as cinco ações básicas de saúde, assistência à gestante e vacinas. Eu copiava e viajava com mais ou menos 120 quilos de material educativo (ENTREVISTA, 1998).

Essas memórias são ilustrativas das muitas articulações entre porta-vozes de diferentes instituições, sejam estatais, religiosas, ou de organismos da sociedade civil em diferentes períodos da história do país. De modo específico, a Pastoral da Criança teve sua gênese vinculada a programas de cooperação, embrionariamente, entre o Unicef e a Igreja Católica representada pela CNBB. Esse Programa inicial se vincula a outros em função de o próprio Unicef e a CNBB desenvolverem programas de cooperação com o governo brasileiro. Em 2003, por exemplo, a maior parte do financiamento à Pastoral da Criança advinha do Ministério da Saúde. ${ }^{5}$ Ao tratar sobre como é investido o dinheiro e de onde vem, Zilda Arns resume:

No plano econômico, o trabalho da Pastoral da Criança possibilita aos governos fazer muito mais com os mesmos recursos; no plano político, estimula a participação social no controle do uso dos recursos públicos; no plano social, ajuda as pessoas a se promoverem, a tornarem-se sujeitos de sua própria história e no plano religioso, possibilita a união da fé com a vida (NEUMANN, 2000, p. 93-94).

Recuando brevemente no tempo, dada a impossibilidade de aqui avançar nesta discussão, as décadas de 1930 e 1940 também exemplificam a cooperação entre os poderes instituídos. O então presidente Getúlio Vargas, ao
5 Em 2003 os recursos provinham de dois principais parceiros: do Ministério da Saúde, arcando com aproximadamente $80 \%$ dos recursos, e do Programa Criança Esperança (Rede Globo/ Unicef), que repassa, anualmente, uma porcentagem do total arrecadado, tendo uma custo de $\mathrm{R} \$ 1,18$ por criança/mês (NEUMANN, 2003, p. 75). Vale lembrar que a Pastoral da Criança passa por controle permanente de gastos em termos internos e externos e mantém um portal transparência disponível em: <https:// wiki2.pastoraldacrianca.org.br/wiki/ Portal_da_Transparência >. 
ampliar a legislação social e trabalhista e dar maior atenção à área social e assistencial, convoca a Igreja Católica a colaborar com suas medidas. De um governo varguista populista, que aparentemente passou a atender reivindicações populares e garantir direitos aos trabalhadores, o presidente afirma-se e concentra-se em ações de caráter emergencial e compensatório, acentuadamente paternalista, autoritário e repressor, contando com a sintonia de pessoas vinculadas à Igreja Católica, instituição com experiência e colaboradora da manutenção da ordem social. É desse período a criação da Legião Brasileira de Assistência (LBA), em 1942, o Serviço Social da Indústria (SESI) e o Serviço Nacional de Aprendizagem Comercial (SENAC), ambos em 1946, no governo de Eurico Gaspar Dutra.

Com essas medidas, o Estado buscou uma solução para se atrelar às iniciativas autônomas e emergentes da sociedade civil, transformando-as em aparelhos estatais a serviço do fortalecimento do seu poder. A caridade outrora exercida pela Igreja é, em certo sentido, substituída pela "caridade" do Estado e pela sua "solidariedade" administrativa (NETO; STEFANI; PEZZI, 2003).

Voltando às décadas mais próximas do objeto foco deste artigo, Costa (2015) indica que o desenvolvimento inicial da Pastoral da Criança ocorre num complexo contexto nacional e eclesial daquelas duas últimas décadas do século XX. O país, no início dos anos de 1980, vivia uma crise econômica e era governado por João Batista Figueiredo (1979-1985), último dos generais que haviam tomado o poder via golpe civil-militar desde 1964. Conforme indica Costa (2015, p. 154-155), "a deterioração da economia brasileira de então impactou profunda e negativamente a sociedade nacional, tendo efeitos particularmente perversos entre a população de baixa renda [...]. As dificuldades enfrentadas pelo país, sobretudo entre suas camadas populares, tornaram tão somente mais necessária a citada Pastoral".

Desde o golpe civil-militar em março de 1964, o Estado assume de forma exclusiva a execução de projetos sociais e tudo passa a ser centralizado sob a ideologia de segurança nacional. ${ }^{6}$ Nesse período ocorre o rompimento do Estado com a sociedade civil, e o governo militar centraliza todas as obras sociais no Estado, criando, para tanto, organismos como, por exemplo, o Movimento Brasileiro de Alfabetização (MOBRAL), em 1968, uma espécie de substituição ao método de alfabetização de adultos, preconizado por Paulo Freire e que recebia recursos estatais até a tomada do poder pelos militares em 1964. É mister destacar que a Pastoral da Criança passa a investir, também, na alfabetização de jovens e adultos nos moldes do método de Paulo Freire:

A Pastoral da Criança passou a investir também na alfabetização de jovens e adultos. Hoje são mais de 22 mil alunos aprendendo
6 A Doutrina de Segurança Nacional, que se torna lei em 1968, tinha por objetivo principal identificar e eliminar qualquer forma de manifestação social, pessoas e/ou grupos que questionassem ou criticassem o regime estabelecido. Esses eram tidos como "inimigos" internos, tendo como principais os comunistas (BUENO, 2014). 
a ler e escrever através das palavras-chave na Pastoral, tais como: soro caseiro, saúde, nutrição, família, comunidade, fraternidade, fé, Deus e outras. [...] a média de tempo necessário para alfabetizar tem sido de 10 meses, a custo de 2 dólares por aluno/mês (NEUMANN, 2000, p. 91-92).?

Toda e qualquer forma de reivindicação nesse período foi tratada com repressão e violência. Embora reprimidos pela ditadura, os movimentos sociais resistiram, cresceram e se desenvolveram no interior de setores da Igreja Católica, muito embora esta tenha atravessado tempos difíceis, como, por exemplo, tensões em torno de perspectivas teológicas e pastorais e da repressão encetada pela própria Sé Romana à Teologia da Libertação, que supunha haver desvios e ideologização da fé. Assim, teólogos guiados pela eclesiologia da libertação foram questionados, as Comunidades Eclesiais de Base (CEBs) perderam apoio institucional e a formação de novos padres sofreu um revés de recondução aos formatos eclesiológicos conservadores. ${ }^{8}$

Contudo, a Igreja Católica empreende um processo de revisão de sua postura política diante dos problemas sociais, ocorrendo uma releitura da concepção de caridade. Nessa releitura, a caridade deixou de ser compreendida como tão somente dar esmolas; houve significativo fortalecimento das comunidades cristãs de base e das pastorais sociais, as quais vincularam a fé a uma ação prática de discutir os problemas sociais à luz do Evangelho.

A nascente eclesiologia da Teologia da Libertação despertou as pessoas para a transformação da realidade. As classes populares e as CEBs, que irromperam nos anos da ditadura, constituíram-se como espaços privilegiados para a formulação dessa Teologia e, como redes pastorais de base popular contrárias à ditadura, em áreas urbanas e rurais uniam fé e reivindicação por melhores condições de vida. Tais comunidades fortaleceram as pastorais sociais que celebravam a fé em vinculação com uma prática política. Para Neto, Stefani e Pezzi (2003, p. 37), a tomada de consciência pelas classes populares passou a ser sinônimo de libertação e tais classes "vão constituir-se nos primeiros atores sociais verdadeiramente autônomos com relação ao Estado e mais tarde com relação à própria Igreja, sendo os precursores das primeiras ONGs brasileiras".

Essas organizações não governamentais, partidos políticos e movimentos sociais, com o apoio de parcela da hierarquia da Igreja Católica, tiveram um papel fundamental para a queda do Regime Militar e para a transição democrática no país. Por meio de suas lutas houve uma reconstrução do conceito de sociedade civil e a inovação das lutas sociais, criando, assim, um novo espaço ético, político e cultural por meio de ações coletivas, nas quais esses movimentos sociais adquiriram também uma função de luta política pela democracia (GOHN, 2000).
7 No método de Paulo Freire, as palavras geradoras começam a surgir no processo de levantamento do universo vocabular dos alunos. Na Pastoral da Criança, o processo é iniciado com as palavras do universo da própria Pastoral. Em Freire, o objetivo da alfabetização de adultos é promover a conscientização sobre os problemas sociais para o conhecimento da realidade social, aspecto também presente na agenda da Pastoral da Criança, talvez de forma mais moderada.

8 A Teologia da Libertação é um movimento socioeclesial que surgiu dentro da igreja católica progressista, na esteira dos movimentos civis e de jovens no Brasil dos anos sessenta do século XX, os quais, movidos por ideais de liberdade, passaram a criticar tudo o que se vincula às práticas autoritárias e centralizadoras da época. Concomitantemente, essa Teologia também influencia os movimentos sociais ao ressaltar as classes populares como sujeitos de seu próprio destino. A fé cristã, em sua reinterpretação analítica e antropológica, é a sua inspiração básica, vivida e entendida como ação transformadora da realidade social. É uma teologia popular, das CEBs, e é capaz de repensar a função social da Igreja. Um dos expoentes mais conhecidos da Teologia da Libertação, no Brasil, é o franciscano Leonardo Boff. Em 1985, Leonardo sofreu um processo disciplinar, foi afastado do ensino e da editoria da Vozes e submetido a um período de recolhimento e silêncio. Todavia, tal ordem e proibição não impediram que conflitos entre o teólogo e a Congregação para a Doutrina da Fé, em Roma, continuassem e, em 1992, Boff abandonou a Ordem dos Frades Menores. Além de Boff, outros podem ser destacados: o jesuíta João Batista Libânio, o frade carmelita Carlos Mesters e o sacerdote secular José Oscar Beozzo. Influenciados pela Teologia da Libertação, seminários, como o arquidiocesano de São Paulo e o de Olinda e Recife, adotaram programas de formação dos seminaristas, inovadores e progressistas (COSTA, 2015). 
Da mobilização popular resulta a Constituição de 1988, o Estado estabelece como princípio básico que a tarefa pública é seu dever e também amplia a participação da sociedade nas políticas públicas, havendo certa inversão "da nossa tradição histórica: o de construir o Estado a partir da sociedade e sob o controle dela" (NETO; STEFANI; PEZZI, 2003, p. 39).

Somente com a aprovação da Constituição de 1988 e pela descentralização política e administrativa é que as organizações obtiveram espaço para uma atuação efetiva e autônoma, expressa por meio da diversidade partidária, da formação dos sindicatos e do fortalecimento da sociedade civil organizada, urbana e rural, fora das estruturas do Estado e do Mercado. Como apontado por Vieira (2000, p. 61), "os atores da sociedade civil organizados em movimentos sociais cumprem função pública, absorvendo a ação comunicativa existente no mundo da vida e levando-a ao nível da esfera pública. Defendem o interesse público e se constituem como instância de crítica e controle do poder".

A partir da década de 1990, o cenário sociopolítico se transforma, há uma sistematização dos movimentos sociais que atuaram dentro da Igreja Católica em organizações populares sem fins lucrativos, independentes do Estado e do Mercado, e são criados os diversos fóruns de articulação das ONGs. É o período em que se começa a discutir e articular trabalhos sobre as mudanças globais, o avanço do neoliberalismo e da globalização. A Conferência das Nações Unidas para o Meio Ambiente e o Desenvolvimento - Eco 92 reuniu ONGs de todo o mundo, tendo como principal objetivo discutir questões ligadas ao processo da globalização e buscar meios de conciliar o desenvolvimento socioeconômico com a conservação e proteção dos ecossistemas mundiais.

Por intermédio dessa Conferência, que teve repercussão mundial, as organizações sem fins lucrativos conquistaram leis no Estado brasileiro que regularizaram suas formas de ação. Também a criação da Associação Brasileira de Organizações Não Governamentais (ABONG), em 1999, vem somar nesse processo, defendendo os princípios de igualdade, diversidade, solidariedade, pluralidade, autonomia, transparência, participação, liberdade, sustentabilidade, democracia e horizontalidade. ${ }^{9}$

Ademais, para regular o relacionamento com o Mercado, foi criado o Grupo de Instituições e Fundações Empresariais (GIFE) que reúne empresas, institutos e fundações privadas que praticam investimentos sociais em organizações da sociedade civil para a promoção de projetos que visam à construção de uma sociedade sustentável. ${ }^{10}$

Vale lembrar que desde os anos de 1970 proliferam discursos que fundamentam as modificações socio-históricas provocadas pelo interesse do capital, especialmente em torno da questão social e de acesso aos direitos. Tais discursos incentivam a necessária participação da sociedade civil diante da "crise" do Estado e ratificam a intervenção
9 Disponível em: <http://www.abong. org.br>. Acesso em: 8 dez. 2017.

10 Carrion (2000) analisa a participação de quatro empresas privadas no terceiro setor, associadas ao GIFE, e nelas identifica a substituição da lógica da caridade pela do investimento social. 
do terceiro setor e das organizações não governamentais (ONGs). É nessa conjuntura que surge a Pastoral da Criança que assume a tarefa de intervir junto às mazelas da sociedade fundamentando-se numa ideia que entrecruza caridade cristã e transformação social.

Dentre as tendências do terceiro setor está a de identificá-lo com a sociedade civil, motivada a ocupar cada vez mais um espaço de intervenção social. Essa alteração, que veio se firmando nas últimas décadas do século $\mathrm{XX}$, resulta de um gradativo processo de o Estado se desresponsabilizar no tocante à questão social, transferindo-a para o mercado e para o terceiro setor. ${ }^{11}$ Tal processo político é resultado do projeto neoliberal que, diante da crise da acumulação capitalista, iniciada em 1970 e intensificada a partir da década de 1990, visa a reestruturação produtiva, as transformações no campo do trabalho e a "reforma" do Estado.

Nesse novo formato de minimização do Estado e maximização dos interesses do capital, os direitos sociais dos cidadãos são transferidos para o mercado e para a solidariedade dos cidadãos de todas as classes. Isso resulta na precarização das políticas sociais de responsabilidade do Estado e na privatização por meio da remercantilização e refilantropização dos serviços sociais, esta caracterizada por Montaño (2003, p. 185) como a "alteração de um padrão de resposta social à questão social (típica do Welfare State), com a desresponsabilização do Estado, a desoneração do capital e a autoresponsabilização do cidadão e da comunidade local para esta função".

Desse modo, subjacente ao processo de proliferação do terceiro setor esteve a política neoliberal, adotada por governos do período. Por exemplo, Fernando Henrique Cardoso, nos oito anos de mandato (1995-2003), "renega" ideias de sociólogo progressista de outrora e segue um modelo neoliberal, no qual a produção de bens e serviços é retirada da esfera estatal e deslocada para o setor privado lucrativo e/ou não lucrativo, a exemplo das organizações não governamentais (ONGs) e das entidades filantrópicas.

Vale ressaltar que em torno do fenômeno do terceiro setor ocorre entendimentos diversos que interferem no tratamento da questão social. O mais conservador e vigente na sociedade pauta-se em um discurso de que nem o Estado, nem o mercado dão conta dos problemas sociais, sendo a sociedade civil movida pelo voluntarismo e solidariedade, chamada a intervir no social.

Segundo Gohn (2003, p. 13-14), os movimentos "representam forças sociais organizadas que aglutinam as pessoas não como força tarefa, de ordem numérica, mas como campo de atividades e de experimentação social, e essas atividades são fontes geradoras de criatividade e inovações sócio-culturais”. Todavia, visando conceituar a expressão terceiro setor, é necessário lançar mão de seu caráter polissêmico, haja vista as muitas denominações que recebe em função de vários tipos de grupos que o compõem.
11 Vale lembrar que o fenômeno do terceiro setor nem sempre existiu no Brasil. Por aproximadamente três séculos ficou circunscrito ao espaço da Igreja Católica ou sob sua direção. A caridade cristã era feita por associações voluntárias que viviam os reflexos de um catolicismo que sofria influência de relações, por vezes complexa, entre Estado e Igreja Católica. Salientamos, também, que a caridade cristã não está circunscrita apenas à Igreja Católica, conforme se pode ver em Silva (2009). Todavia, a opção de aqui tomar o exemplo da Igreja Católica se deve ao fato de a Pastoral da Criança ser um organismo dessa Igreja e de sua fundadora, Zilda Arns Neumann, professar essa confissão religiosa desde a infância e que é constantemente vivificada por suas práticas de rememoração. 
Nesse amplo leque, há as organizações que se afirmam privadas alegando não terem fins lucrativos; há as que se inscrevem numa concepção clara de interesse público, como, por exemplo, as conhecidas como Organizações da Sociedade Civil de Interesse Público (OSCIP). São as OSCIPs que instituem o termo "parceria" e foram aprovadas pela Lei 9.790, de 1999. Além do reconhecimento estatal, essa Lei permite que o Estado financie organizações que trabalham em prol da sociedade, ficando assim instituídas as parcerias público-privadas. ${ }^{12}$

Essa forma associativa, com preocupação essencialmente social e cidadã, é formada pelas organizações que rearticulam o Estado e o mercado, passando responsabilidades sociais para as organizações da sociedade civil. Essas organizações se transformam em espaços de participação e experimentação de novos e diferentes modos de pensar e agir sobre a realidade e de luta por justiça social.

Na década de 1970, que antecede a implantação da Pastoral da Criança, a Igreja Católica, se não como instituição, mas parcela significativa de bispos, padres, freiras e leigos, junta esforços aos das organizações surgidas nas décadas de sessenta e setenta do século XX, que forjaram um projeto de resistência e de denúncia aos governos ditatoriais do período.

Nessa direção, por meio das CEBs, que fundamentam sua ação nos princípios da Teologia da Libertação, antigas alianças entre a Igreja Católica, o Estado e as classes dominantes sofreram reveses, não somente por questões teológicas e pastorais, mas também ideológicas e políticas.

A participação do terceiro setor na área de políticas públicas no Brasil passa a ser essencial para o surgimento de projetos, leis e experiências que auxiliem na inclusão e recuperação social e econômica de segmentos carentes da sociedade. Foi por meio da participação ativa e da pressão de instituições não governamentais sobre o Estado que foram elaborados:

O Estatuto da Criança e do Adolescente ECA, a Lei Orgânica de Assistência Social LOAS, a Reforma Sanitária que levou à criação do SUS - Sistema Único de Saúde, a luta pela Reforma Urbana, as Câmaras Setoriais da Construção Civil, as Câmaras dos Usuários do Sistema de Transportes Coletivos, as experiências de Orçamento Participativo em diferentes cidades brasileiras, os diferentes conselhos gestores de políticas de habitação, os direitos da mulher, das pessoas portadoras de deficiências, dos idosos, das escolas, e outras formas de colegiados e estruturas de mediação entre o Estado e a sociedade civil (GOHN, 2000, p. 64).

Desse modo, as organizações do terceiro setor buscam cada vez mais parcerias entre o setor público e privado
12 Conforme o artigo $9^{\circ}$ da Lei 9.790/99, a parceria é um instrumento firmado entre o poder público e as entidades qualificadas como OSCIPs. Esse vínculo de cooperação entre as partes visa fomentar a execução de atividades de interesse público. 
e a sociedade civil na implementação de políticas públicas, especialmente as voltadas para o campo social. A Pastoral da Criança figura entre essas organizações que, no discurso de sua fundadora, tem "um papel decisivo na justiça social, para que todos tenham acesso a uma vida mais digna" (ENTREVISTA, 1998); que "a construção de um mundo justo e fraterno depende, em primeiro lugar, de cada um de nós e de nossas atitudes; por isso se torna tão importante a valorização do Terceiro Setor para a construção da justiça e da paz" (NEUMANN, 2003, p. 130). ${ }^{13}$

A recepção da Pastoral nas dioceses foi bem-sucedida e transformou-se em uma das organizações do terceiro setor que reúne o maior número de voluntários do país, tornando-se, segundo Zilda Arns (2003), uma "experiência consagrada”. É um organismo da ação social da CNBB, uma instituição filantrópica, voluntário-religiosa, reconhecida nacional e internacionalmente pela atuação no combate à desnutrição e mortalidade infantil.

\section{Testemunho e prática educativa transformadora de Zilda Arns}

Sinto como uma luz divina dentro de mim. Quando comecei a imaginar a Pastoral da Criança, senti como se Deus me inspirasse e que o caminho iria dar certo. E está dando certo no Brasil e no mundo inteiro. Então, é uma vocação, é uma certeza de ser guiada por Deus e que tenho, como cidadã, um papel decisivo na justiça social, para que todos tenham acesso a uma vida mais digna. [...] realmente me apaixonei muito pelo trabalho e a gente viu um resultado extraordinário (ENTREVISTA, 1998).

Nessa entrevista e nos outros três documentos de sua autoria, já referidos, Zilda Arns constrói uma narrativa em que se remete constantemente à missão da Igreja Católica, a de participar da construção de uma sociedade justa e fraterna. Diz que esses são os objetivos da CNBB e que a Pastoral da Criança também participa dessa construção. Faz uma leitura da realidade que vai além da mera caridade cristã, que precisa de um conjunto de profissionais com preparo técnico, muito embora não desprovidos de uma mística que associe fé e obras, "corresponsabilidade social, cidadania”; uma fé não alienada dos problemas sociais reais.
13 Há estudos da Pastoral da Criança sob outras perspectivas, tal como a de gênero que se encontra em Anjos (2007).

[...] o trabalho a ser desenvolvido exige o envolvimento de técnicos qualificados de diferentes áreas, assistentes sociais, psicólogos, pedagogos [...]. Para criar uma relação horizontal, minimamente igualitária entre atendidos e voluntários, seria necessário que o discurso dos coordenadores dessas pastorais 
fosse colocado em prática, ou seja, a defesa dos direitos individuais e coletivos, o trabalho solidário. Entretanto tal fato exigiria o questionamento e a superação dos próprios valores morais e cristãos, já que haveria uma abertura e conseqüente compreensão da realidade social em que vivem, possibilitando elaborar novos valores morais e espirituais (ENTREVISTA, 1998).

Esse fragmento é indicativo de que Zilda Arns acompanhava o processo de renovação da eclesiologia da época e pensava nas misérias do país à luz do credo religioso por ela professado. Na entrevista concedida em 2003, informa que a Pastoral da Criança atendia mais de 1,5 milhão de crianças com menos de 6 anos de idade e quase 80 mil gestantes, além de realizar outras atividades sociais em 3.549 municípios. Para Zilda Arns, o êxito da Pastoral decorria da união da fé com a vida, do engajamento das pessoas movidas pela mística fraterna de construir um mundo melhor, da participação comunitária, da metodologia de ação que relacionava saúde e educação; da Pastoral ser parceira para que a saúde pública chegasse às bases que são as famílias, da fidelidade aos seus objetivos que são a luta para reduzir a mortalidade infantil, a desnutrição e a violência e para promover educação às mulheres. Além disso, a Pastoral tem como ponto principal a criança no contexto da família e da comunidade (ENTREVISTA, 2003, p. 64-66).

Zilda destaca que o trabalho da Pastoral da Criança é transformador, impulsionado pelo compromisso com o evangelho e a cidadania. Ao ser indagada sobre a participação dos não católicos, responde: "Temos como mestre Jesus Cristo e ele disse que todos devem ter vida em abundância. Não disse isso somente para os católicos" (ENTREVISTA, 2003, p. 67), indicando, assim, seu espírito ecumênico. Fala sobre a metodologia colocada em ação pelos mais de 150 mil voluntários da Pastoral da Criança, baseada nos ensinamentos de Jesus Cristo e que "isso significa conjugar verbos que às vezes parecem esquecidos como amar, incluir e respeitar o diferente" (NEUMANN, 2000, p. 87).

Dentre as ações concretas e tidas como urgentes estão a alimentação enriquecida e a vigilância nutricional, que garantem qualidade de vida para crianças, gestantes e famílias. Com os alimentos disponíveis na comunidade, os líderes ensinam a produzir pratos de alto valor nutritivo, sem desperdícios. Cascas de ovos, talos e cascas de verduras, legumes e frutas, como, por exemplo, a pupunha da Amazônia, cajus e castanhas do Nordeste, folhas verde-escuras e farelos de arroz e de trigo, amendoim, soja, gergelim, girassol, e muitos alimentos normalmente jogados fora são incluídos em receitas baratas e nutritivas (NEUMANN, 2000, p. 87-88).

As estratégias do trabalho da Pastoral são continuamente aperfeiçoadas, como, por exemplo, os materiais 
educativos e a formação de líderes, em que são estimuladas a educação para a saúde, a nutrição, a educação, a cidadania, a paz e a fé. Igualmente, são aperfeiçoados o sistema de informação, que recebe os dados dos indicadores de resultados, a articulação e a soma de esforços com os serviços governamentais, entre outros.

\section{Considerações finais}

As ações vinculadas a uma perspectiva de caridade cristã foram (re)significadas pela prática social educativa por melhores condições de vida e colocadas em marcha pela Pastoral da Criança sob a liderança de Zilda Arns. Num país como o Brasil, marcado pelo autoritarismo e por uma desigualdade social ímpar, as organizações que compõem o terceiro setor sempre foram de extrema importância na consolidação de espaços democráticos, nos quais as pessoas possam fazer valer sua cidadania na construção de um mundo de condições dignas para todos.

A Pastoral da Criança, assim como outras organizações do terceiro setor, frutos de organizações da sociedade civil que se articula por meio de ações próprias visando ter um controle do poder para solucionar seus problemas mais urgentes, também reformula as ações do Estado, tanto em relação às políticas públicas, quanto em torná-lo um espaço democrático e de participação política e social.

A "experiência consagrada" de Zilda Arns contribui para instaurar, no Brasil, uma cultura para a cidadania e passa a cumprir um papel mediador entre a esfera privada da família e a esfera pública do Estado. Nas comunidades, tal experiência torna-se o lócus da convivência e da realização de novos sentidos para a compreensão da realidade e o exercício de cidadania. Enfim, a Pastoral da Criança se orienta para a missão de construir um mundo sustentável, com justiça social, solidariedade e respeito aos direitos humanos, culturais, ambientais e sociais, valores ainda tão necessários nos tempos de hoje. Em seu trabalho de memória, Zilda Arns reitera com intensidade:

Deus está guiando todos os passos da Pastoral, e essa semente se espalha gradualmente a todos os países onde há fome de pão e de justiça social e precisa ser cuidada para cair em terra boa e dar muitos frutos. [...] O maior segredo é trabalhar por amor e formar redes de solidariedade humana que escuta o clamor do povo e procura alcançar a paz, participando da construção de uma sociedade justa e fraterna, a serviço da vida e da esperança, para que TODOS TENHAM VIDA E A TENHAM EM ABUNDÂNCIA (Jo 10, 10). (NEUMANN, 2000, p. 96-97. Grifos do autor).

Foi no movimento de colocar-se a caminho como sempre fez, Zilda Arns estava lançando a pedra fundamental 
da Pastoral da Criança entre os desvalidos do Haiti, quando, lamentavelmente, foi atingida pelo terremoto que ocasionou sua morte, em 12 de janeiro de 2010. Almejamos que as sementes lançadas por Zilda Arns continuem germinando e dando frutos de solidariedade e de justiça.

Assim como na fábula de Esopo, na qual o mais importante foi o pai ter sido ouvido pelos filhos, esperamos que as memórias de Zilda Arns sejam ouvidas e passem de geração em geração entre líderes comunitários; que não haja perda da experiência e que não leve ao desaparecimento da narrativa que tem sua fonte na comunidade que compartilha e transforma determinada tradição ao longo das gerações.

Trata-se de uma exigência de memória contrária ao esquecimento e às várias formas de apologia que desembocam na construção de mitos. Longe de se pensar que a filosofia benjaminiana seja portadora de prescrições, uma vez que ela própria é um permanente convite a rechaçar fanatismos, concluímos com um convite nesse caminho: o de não ficarmos mudos tal como ocorreu com os sobreviventes que voltaram das trincheiras da guerra, não mais assimilando o trauma; nem sejamos aqueles que, movidos pela indiferença ao sofrimento alheio, levantam-se e vão embora. Sejamos testemunhas no sentido de uma retomada reflexiva do passado, estreitamente vinculado ao tempo presente, a fim de que na interrupção desse tempo possamos fazer ressurgir a esperança de Zilda Arns, ainda não totalmente concretizada.

\section{Referências}

ALBERTI, Verena. Ouvir contar: textos de história oral. Rio de Janeiro: FGV, 2004.

ANJOS, Gabriele dos. Maternidade, cuidados do corpo e "civilização" na Pastoral da Criança. Estudos Feministas, Florianópolis, v. 15, n. 1, p. 27-44, jan./abr. 2007

BENJAMIN, Walter. Magia e técnica, arte e política: ensaios sobre literatura e história da cultura. Tradução: Sérgio Paulo Rouanet. São Paulo: Brasiliense, 1987.

BERTOL, Sueli Aparecida; PAULA, Ercília Maria Angeli Teixeira de. Pastoral da criança: estado da pesquisa no Brasil. Disponível em: <http://www.pucpr.edu.br/eventos/educere/educere2006/anaisEvento/docs/CI-184-TC. pdf $>$. Acesso em: 15 jan. 2018.

BOURDIEU, Pierre. A ilusão biográfica. In: AMADO, Janaína; FERREIRA, Marieta de Moraes (Org.) Usos \& abusos da história oral. 8. ed. Rio de Janeiro: FGV, 2006, p. 183-191.

BUENO, Bruno Bruziguessi. Os Fundamentos da Doutrina de Segurança Nacional e seu Legado na Constituição do 
Estado Brasileiro Contemporâneo. Revista Sul-Americana de Ciência Política, v. 2, n. 1, p. 47-64, Pelotas (RS), 2014.

CALEGARE, Marcelo Gustavo Aguilar; JÚNIOR, Nelson Silva. A "construção" do terceiro setor no Brasil: da questão social à organizacional. Psicologia Política, v. 9, n. 17, p. 129-148, Porto Alegre (RS), 2009.

CARRION, Rosinha Machado. Organizações privadas sem fins lucrativos: a participação do mercado no terceiro setor. Tempo Social, São Paulo, USP, v. 12, n. 2, p. 237-255, 2000.

COSTA, Marcelo Thimóteo da. Pensando o Brasil: discurso religioso e prática social segundo Zilda Arns. Estudos Históricos, Rio de Janeiro, v. 28, n. 55, p. 151-168, jan./ jun. 2015 .

ENTREVISTA com Zilda Arns Neumann. Lições da Pastoral da criança. Estudos Avançados, São Paulo, v. 17, n. 48, p. 63-75, 2003.

ENTREVISTA com Zilda Arns Neumann, gravada por José Wille em janeiro de 1998. A história de Zilda Arns, fundadora da Pastoral da Criança. Portal Memórias Brasileiras. Disponível em: < http://www.jws.com.br/2017/12/ memoria-paranaense-a-historia-de-zilda-arns-fundadora-da-pastoral-da-crianca/> . Acesso em: 21 jan. 2018.

GAGNEBIN, Jeanne Marie. Memória, história, testemunho. In: BRESCIANI, Stella; NAXARA, Márcia (Org.). Memória e (res)sentimento: indagações sobre uma questão sensível. Campinas: Unicamp, 2004, p. 83-92.

GOHN, Maria da Gloria. (Org.). Movimentos sociais no início do século XXI: antigos e novos atores sociais. Petrópolis: Vozes, 2003.

Mídia, terceiro setor e MST: impactos sobre o futuro das cidades e do campo. Petrópolis: Vozes, 2000.

LÉVILLAIN, Phillipe. Os protagonistas: da biografia. In: REMOND, René. Por uma história política. 2. ed. Rio de Janeiro: FGV, 2003, p. 141-184.

LÖWY, Michael. Walter Benjamin: aviso de incêndio: uma leitura das teses "Sobre o conceito de história". Tradução: Wanda Nogueira Caldeira Brant. Tradução das teses: Jeanne Marie Gagnebin e Marcos Lutz Müller. São Paulo: Boitempo, 2005.

MONTAÑO, Carlos. Terceiro setor e questão social: crítica ao padrão emergente de intervenção social. 2. ed. São Paulo: Cortez, 2003. 
NETO, Antônio; STEFANI, Monalisa; PEZZI Junior, Sady. Gestão de marketing para organizações do terceiro setor. Londrina: Midiograf, 2003.

NEUMANN, Zilda Arns. Pastoral da Criança: uma experiência consagrada, Cadernos Adenauer: Fé, Vida e Participação, São Paulo, v. 9, s/n, 2000, p. 83-98.

. Zilda Arns Neumann: ela criou uma rede de solidariedade que salva centenas de milhares de crianças brasileiras. Belo Horizonte: Leitura, 2003.

SILVA, Claudia Neves da. As ações assistenciais promovidas pelas igrejas pentecostais: motivações e dificuldades. Estudos de religião, São Paulo, v. 23, n. 36, 35-60, jan./ jun. 2009.

VIEIRA, Liszt. Cidadania e globalização. 4. ed. Rio de Janeiro: Record, 2000.

Recebido em: 22/01/2019 Aprovado em: 21/03/2020 Publicado em: 01/04/2020 